\title{
Global citizenship cultivation through the COIL-PBL model: case study of the Great Debates course
}

\author{
Greg Tuke', Sonia Kapur², and Karim Ashour ${ }^{3}$
}

\section{Abstract}

he current global political, economic, and social challenges urge the need to cultivate global citizenship among students in their learning process. This paper

L presents the role of Collaboration Online International Learning (COIL) using the Project-Based Learning (PBL) approach in cultivating global citizenship among university students. The paper explains the different implementation challenges of a COIL course on the different levels and core design elements of the COIL-PBL model to overcome such challenges. Empirically, this paper presents a primary case study of the Great Debates course that was implemented in different forms by three partner universities, which are the University of Washington Bothell (UWB), the University of North Carolina Asheville (UNCA) in the USA, and the Future University in Egypt (FUE). The implementation showed a positive impact on cultivating global citizenship among participating students, which is clear from developments in students' skills in the areas of cross-cultural communication and negotiation, cultural sensitivity and tolerance, teamwork and coordination across virtual global teams, analytical skills, and perception toward other cultures and society. Notably, the COIL-PBL model has started to gain further popularity after the COVID-19 pandemic as an alternative for physical mobility, which encourages future research in this area using other implemented courses using the COIL-PBL model.

\footnotetext{
1. Seattle University, United States; greg@goingglobalu.com; https://orcid.org/0000-0002-5309-4659

2. University of North Carolina, United States; skapur@unca.edu; https://orcid.org/0000-0001-5305-414X

3. American University in Cairo, Egypt; k.ashour@aucegypt.edu; https://orcid.org/0000-0003-4159-2113
}

How to cite this article: Tuke, G., Kapur, S., \& Ashour, K. (2021). Global citizenship cultivation through the COIL-PBL model: case study of the Great Debates course. Journal of Virtual Exchange, 4, 80-91. https://doi.org/10.21827/jve.4.35815 


\section{Keywords: COIL; PBL; global citizenship; Great Debates.}

\section{Introduction}

Globalization and internationalization have created new societal trends at all levels of society, be it social, political, or cultural. Consistent with this trend, there has been an emergent need to bring in changes in the field of education, whereby students must be equipped with the knowledge, skills, and attitudes to face the challenges and contribute in significant ways to resolve global challenges (Farahani, 2014; Knight, 2004; Krebs, 2020). This implies that universities are now, more so than ever before, paying attention to the need to prepare students to meet the new realities of the changing world. Within the framework of a liberal arts education, universities now focus on efforts to cultivate global citizens, from the perspectives of being humanitarian, doing business in any field, and communicating virtually.

While the idea of a global citizen is age-old, deriving its origins from Ancient Greece, there has been a resurgence of the term within university campuses and the fields of education (Schattle, 2010). However, what complicates this situation is the broad definition and idea of what constitutes global citizenship as scholarly literature varies on its definition. Based on some of the common themes that emerge from the literature, a global citizen is broadly conceptualized as "someone who can exercise responsible leadership to promote positive change and build a sustainable world” (Reade et al., 2013, p. 100). Thus, sustainability running across all the key aspects of society has been identified as an important goal of being a global citizen (Handa, 2018; Scheunpflug \& Asbrand, 2006). Other threads of the global citizenship idea are issues of collaboration, activism, and social justice among others (Rapoport, 2020).

Taking these broad ideas of global citizenship leads us to question and define how best to translate these ideas into an actionable agenda to cultivate global citizenship among students. In the realm of education, for cultivating global citizenship, three clear strands of action emerge from the existing literature; global citizenship as knowledge creation, skill formation, and attitude generation. Interestingly, how the ideas translate into action varies across cultures based on how global citizenship is perceived. In a study across three cultures, the USA, India, and Bulgaria, significant differences were noticed in how people from these societies responded to the question. In the USA, the emphasis is on understanding and knowing about the other cultures; Bulgaria on freedom and ability to travel, and India on the need for connecting with others as well as the global good (Iva, Stephen, \& Nandini, 2012). 
To achieve the objective of cultivating global citizenship stated above, universities across campuses have a range of measures. Commonly, many universities have study abroad programs wherein students go abroad physically, experience a culture, make connections, and return back enriched with the knowledge of the particular society and culture. Moreover, many universities participate in different virtual exchange programs wherein students engage virtually in discussing global issues and problems. These models vary based on the kind of emphasis and focus that is placed on cultivating some aspects of global citizenship more so than others.

Notably, while a range of programs is offered at universities to foster global citizenship, the challenge is to design programs that cut across and combine disciplines (Stearns, 2009; Zinser, 2012). The process of broadening minds and embracing differences is an experience that occurs when students work with and discuss and share ideas with those who bring different perspectives. Significantly, it is further enhanced when students from different disciplines work collectively (Sexton, 2018). In this paper, we share our experience of implementing such a program.

The Internet has been considered the driving force of globalization (Borcuch, Piłat-Borcuch, \& Świerczyńska-Kaczor, 2012). Recently, educational institutions have started to take advantage of this advancement in technology and base their education on the recently emerged COIL model. This model "involves the co-development of a course module by two or more instructors from different countries, each of whom recognizes that a valuable kind of learning occurs when students from different parts of the world work together on a common area of focus” (University of Minnesota Duluth, n.d.). The most essential learning value of COIL, however, comes in the actual design of how students collaborate. According to the authors who implemented multiple PBL courses, it is found that there is no better course design approach than PBL as it is student-centered and instructorfacilitated, which allows students to learn by actively engaging in real-world and personally meaningful projects. The simplest definition of PBL is a course design that has students collaborating to find solutions to meaningful, challenging real-world problems, over an extended period of time. Project-based learning moves the learner toward depth and toward the higher-order skills used in applying content (PBLWorks, n.d.). In today's world where it is argued that knowledge is doubling every three to five years, it is a challenge to keep pace with the new knowledge (Gilbert, 2005). Understanding how to get needed information quickly, accurately, and efficiently, and then knowing how to use that information to problem-solve effectively is the core principle of learning in PBL. Importantly, these are the skills that are of greatest value and demand to business leaders worldwide (World Economic Forum, 2018).

Accordingly, this paper has an interest in focusing on the role of COIL using the PBL approach in cultivating global citizenship and influencing students' mindset and interpersonal skills. Specifically, 
this paper presents the COIL-PBL model by explaining the common challenges in COIL courses and the core elements to be considered in the process of designing a course for successful and impactful implementation. Significantly, this paper presents a primary case study on the Great Debates course within the scope of the COIL-PBL model that was implemented by three partner universities, which are UWB, UNCA, and FUE.

\section{The COIL-PBL model}

Based on our experience of implementing collaborative projects at an international level, we identified some core elements that must be integrated into the design of the program. Each of these elements must be thought through well before they become part of the project design. In thinking through these aspects, it is important to remember that the elements of each project may vary based on the objectives, student body, and the nature of the project. We first list these elements below and then explain each of these elements as they relate to our project design.

The first element is a laser-focus on key learning goals. All COIL courses with a PBL design will have four main areas for learning with concrete ways to assess each; acquisition of specific knowledge, outcome benchmarks for problem-solving in global teams, demonstration of empathetic crosscultural understanding and humility, and effective use of virtual communication that leads to understanding.

The second element is the identification of challenging, meaningful, and authentic problems to address. The problems that are selected in the course design need to be authentic, solvable, and carry some meaning and importance to the students who take on the challenging problem. Finding solutions or partial solutions to the problem should be possible, but not easy.

The third element is sustained inquiry. In order to move toward a proposed solution(s), it is essential to conduct research, reflection and further inquiry over time. Ideally, it should require looking at possible solutions from multiple perspectives.

The fourth element is student-driven, with choices for student voice and teamwork. Global teams should be designed so that all members of the global team interact frequently and across multiple virtual platforms. Accordingly, students can experiment and learn which technology tools are best for which forms of communication and for which stages of problem-solving and interpersonal tension-levels. The global teams determine how they will accomplish the work and drive the process. 
The fifth element is the Reflection and Redo Opportunities, which is essential throughout the course, including individual reflections, global team reflections, and whole-class reflections. The one who offers reactions to these reflections should also vary, including reactions from the professor, other members of the global team and, at times, the class as a whole. One of the most impactful reflections can occur when the faculty member is reflecting upon his/her experience in working in their own 'global team' with the other professor, offering insights as to what is being learned, mistakes made while working cross-culturally, and encouraging reactions from the class to those insights. This powerful lesson - that we are all learners and mistake-makers in this process, including the professor - can have a profound impact on students learning about how power dynamics across cultures, countries, and roles can impact communication and understanding.

\section{The Great Debates course as a case study of COIL-PBL model}

The Great Debates course was implemented within the framework of COIL-PBL, and involved UWB, UNCA, and FUE. It was implemented for four different cohorts of a total of 157 undergraduate social sciences students over four different semesters throughout 2017 and 2018. The first round included UWB, UNCA, and FUE, with a total number of 48 participating students, while the other three rounds included only UNCA and FUE with a total number of 109 students, (second round: 39 students, third round: 34 students, fourth round: 36 students), with an almost equitable share of each university. The English language was chosen as the main tool of communication, providing a common language, as it is considered the official university language among the three participating universities. Students from the three universities engaged together in readings, research, discussions, as well as debating key global issues through video conferences and social media tools which have been assessed as important ways to promote learning (Ansar \& Khan, 2020). This section mainly analyzes the design and implementation of the Great Debates course through the COIL-PBL model.

\subsection{First element: laser-focus on key learning goals}

Each partner institution had different objectives, based on the core course they were each teaching, yet together agreed to some common key learning goals. The Great Debates course was part of a Humanities course at UWB and UNCA, while at FUE the core course focused on developing interpersonal skills in the global political and economic context. Regardless of the difference, there were commonly agreed objectives related to increasing understanding across cultures, addressing social issues within global context issues, developing communication and collaborative research skills through virtual tools, and enhancing debate skills across cultures. 


\subsection{Second element: identification of challenging, meaningful, and authentic problems to address}

The second design element was conducted through different rounds of brainstorming among the three faculty partners prior to the course implementation, considering a wide range of social, economic, and political global contemporary issues. Ultimately, the faculty agreed on ten contemporary and contentious social issues. Each was then posed as a debatable statement. Issues dealing with marital rights and traditions, LGBT rights, political freedom, economic justice, and women's rights were among the issues chosen. These ten debate topics were then presented to the students with each student identifying the two issues of greatest interest to them. Based on those preferences, students were put in one of five global teams, composed of ten students (three to four students from each country). Each global team then further divided up into pro or con sides for each of their two issues, with members of three universities being represented on both the pro and con side of each issue. This ensured that everyone would experience the cross-cultural interaction and decision-making.

\subsection{Third element: sustained inquiry}

The third design element was to ensure that there was a sustained inquiry. The first two weeks focused on global team members engaging in structured and unstructured communication that helped team members to form early-stage personal relationships and to uncover each other's strengths, communication styles, and personalities. This phase is critical to the development of effective problem-solving teams, and is a phase often overlooked when faculty members begin doing their first COIL courses, just as it is in many workplaces. Google, in an extensive two-year study to uncover the elements for effective problem-solving teams, found that the ability to create group norms that encouraged empathetic relationships and full participation of all members were the two critical elements to achieve team success (Duhigg, 2016). By the third week, students in each university conducted a mock debate (on debatable issues not part of the original ten issues selected), to prepare the students for the global debates among the three universities.

These five teams, each with a pro and con side, were tasked with researching the issue, honing the arguments, and then performing and recording a debate virtually, followed by a team-critique and full class reflection on each of the five mock debates. Roleplaying is a common strategy used in COIL courses to provide students with an early low-stakes learning experience in which to practice working virtually and anticipate and address possible cross-cultural challenges that arise.

Students then reflect as a global team on the results of their debate, the lessons learned in performing the debate virtually, and analyzing their global team process in terms of group roles 
and group dynamics. Following each team's self-analysis, the whole class and instructor provided feedback as well.

During the course, students and their teams were scored for participation and insightful analysis rather than performance to keep the stakes lower, and focused on the process of learning, as opposed to the outcome. Following this first round of mock debates, students were given two weeks to research and prepare for each of their two live virtual global debates with their global team. In structuring the course this way, students have a sustained inquiry on three key issues and then opportunities to practice and reflect on their performances and learning, in an increasingly higher stakes testing.

\subsection{Fourth element: choices for student voice and teamwork}

While it may seem much easier for students to communicate if partners are in a somewhat similar time zone, having large 8 to 14 hour time zone differences creates more opportunities for students to learn how to communicate and problem-solve effectively in asynchronous ways. This creates more opportunities for students to explore how to have a discussion using students' produced short videos, where information and ideas are summarized succinctly, thoughtfully, and in interesting, compelling, and persuasive ways. For instance, instead of sending texts or emails that summarize the research findings for an argument by the Egyptian side of a global pro-argument team, the sub-team meets and at the end of the meeting, plans and produces a two-minute video of the salient points, and posts on the closed Facebook page of that global team. The next morning the other half of that pro-side global team watches the video and then reacts with their own video clip. In this way, the information contains far more visual, emotional and relational information than a normal text, and simulates more closely a synchronous, in-person meeting of all group members. Yet it has the added advantage of allowing time for a more thoughtful and succinct response.

Students in each global team used a variety of simple but effective means for sharing ideas and solving the problem they were confronted with; how to develop a coherent set of arguments that would persuade and refute potential arguments from the opposition in the debate. At times, students might choose to do live video chats with some or all members of the team (outside class hours), or record video clips summarizing their ideas, or use live texting or asynchronous emails. Depending on whether the conversation called for brainstorming, or decision-making, highly charged conversations or simple intellectual discussions, students learned which communication tool was best to use for which conversation. It also allowed for more variation so students could use the mode of communication that was closer to their strengths (written, auditory, or visual). 
Students also learned when to call a full meeting of the global team, when to work individually, and when to work in a subgroup.

Finally, it is useful to have students learn some basics about group dynamics and essential group roles that must be played to ensure good teamwork that results in high-performing decision-making. All these higher-order skills are critical for students to develop so they can apply them to the highly networked work world where problems are commonly solved in diverse teams working virtually and globally.

\subsection{Fifth element: reflection and redo}

Like many flipped classrooms, much of the delivery of content happens online, with recorded videos and links to articles and research being posted by the instructors and viewed outside of class time. In class, most of the time is spent reflecting upon what has been read or learned in the vibrant interactions happening outside of class among the global peers. Roleplaying and interactive exercises, followed by more reflection around key themes, like understanding group dynamics, is also another common type of activity in PBL embedded COIL courses.

In the Great Debates course, students had the opportunity to conduct a mock debate within their class before starting their international debates. The two international debates were conducted live in the classroom (USA students arriving early to class, with the Egyptian students staying late due to time zone differences) so that the debate could be conducted in front of both full classrooms, including invited experts in the field of the debate topic and tactics. At the end of the three debates, each team self-evaluated their performance, the class rated each team, and the experts from the various fields provided further feedback on the quality of performance. In this way, the stakes and evaluation got increasingly more rigorous over time and offered time to practice.

\section{The role of Great Debates course using COIL-PBL in global citizenship cultivation}

As outlined above, the objective and design of the course is to cultivate global citizenship. Accordingly, faculty partners rolled out a unified anonymous mini-survey among students who participated in the Great Debates course at UNCA and FUE. On the limitations side, the data collection was not conducted on the UWB side. The data was collected from three different cohorts of a total of 109 students (respondents) from UNCA and FUE by the end of each semester over three different semesters in 2017 and 2018. Specifically, the mini-survey covered five closed-ended 
questions with an option to write a comment/example as elaboration for their answer to each question. The survey covered questions to measure the degree of development in students' skills in the areas of cross-cultural communication and negotiation, cultural sensitivity and tolerance, teamwork and coordination across virtual global teams, analytical skills, and perception toward other cultures and society. Afterward, the results from both universities were aggregated and calculated in percentages.

The results of the survey showed strong and positive student outcomes, which could elucidate the impact of the explained key design elements. First, $84 \%$ of students reported that they developed cross-cultural communication and negotiation skills and became more self-confident in expressing their ideas and perspective across different cultures. One of the students from FUE wrote, "I thought that 'globalization' ended the case and maybe now most of us share the same way of thinking, however during this course, I noticed still our opinions are affected by our own cultures". Second, $73 \%$ of students reported that they gained cultural sensitivity and tolerance skills through discussions of highly sensitive topics and learned how to discuss them on a mature level with their counterparts. For instance, among sensitive topics was the same-sex marriage topic that is considered an extreme taboo issue in Egypt. One of the students from the UNCA side wrote, "the course offered a unique opportunity to reflect on major issues from different perspectives; helping to be more compassionate and considerate of other people's opinions especially when they are very different from mine". Third, $82 \%$ of students reported they developed their teamwork and coordination skills across virtual global teams. Notably, as observed from the faculty partners, some challenges helped students to develop their skills in this area such as navigating different time zones and finding a proper time for all the team members to meet, dealing with disparity among students' knowledge or age, or managing students who sought to dominate in a group. Fourth, $61 \%$ of students reported that they developed their analytical skills through the research, discussions, and debate of complicated global policies while operating in a global virtual team.

Significantly, this course helped students to break some stereotypes about other cultures, with $86 \%$ of students reporting that the course helped them more accurately understand the other culture and society. It was noted by faculty partners from the USA and Egypt that students' perceptions of each other were mainly shaped by media and movies. The interaction among students from both sides came as a shock and surprise for many of them. On the USA side, students did not expect those progressive aspects of Egyptian society or even the level and degree of understanding the students in Egypt had about America or its culture. On the Egyptian side, students did not perceive the economic hardships that students in the USA (most of whom need to work and study at the same time to finance their studies) face. This realization by the Egyptian 
students of the dilemmas that American students face living in one of the 'most developed' countries and yet having to work to finance their education was an eye-opener on how 'developed' economies and societies work.

Therefore, the students' outcomes were that students were not only presenting their ideas in the class but presenting to convince and persuade different audiences with diverse cultures through working in a global team using virtual tools, a far more complex and challenging task than a more traditional debate in a university debating course. Significantly, these aforementioned impacts and gained skills, knowledge, and values by students are considered the powerful added value of the COIL-PBL and are of prime importance for global citizenship.

While there are many advantages to applying a COIL-PBL model project, it is also important to briefly state that implementing such a project requires a lot of planning and preparation to address the problems as they emerge during the project. As the authors have implemented multiple COIL courses among different universities, disciplines, and cultures, it is found by the authors that the implementation of a COIL course presents five common and several significant challenges.

The first challenge is related to the matchmaking process between the potential partner professors who seek to find a complementary fit in their approach to teaching. The second challenge is determining if there is a complementary fit between student groups in terms of content knowledge. The third challenge is on the institutional level, which is based on the willingness and flexibility of potential partner institutions to redesign a university course to incorporate COIL strategies. The fourth challenge is on the logistical side, which could be explained in terms of timing, class-size, technology availability, and time zone. The fifth challenge is on the communication level in which the partnering faculty members determine ways for the students in the two (or more) classrooms to communicate effectively together to accomplish the course learning goals. Therefore, the authors present five core elements of the COIL-PBL model in the process of designing a course for successful and impactful implementation.

\section{Conclusion}

The Great Debates course offers a clear example of how the COIL-PBL model facilitates the cultivation of global citizenship. Specifically, debating different controversial global, economic, social, political, and environmental issues through using innovative virtual tools helped to develop students' cultural intelligence and global mindset. Significantly, this course allowed students to 
work in small global teams, through increasingly more challenging tasks and interacting with an authentic global audience. Moreover, the added powerful learning opportunity with the Great Debates course within the framework of COIL-PBL is that it supports the development of essential skills for being a global citizen including cultural and virtual communication skills, and problemsolving in a global team.

The COIL course partnerships often initially look like potential mismatches between fields of study, quarter versus semester, time zones, and level of student knowledge/age. What is critical, however, is that the faculty members sense that they have a good complementary fit in terms of personality, overall learning goals and approaches to teaching, and have enough overlap in similar curriculum plans to be meaningful. Notably, matchmaking on individual levels would not be enough unless there is flexibility and willingness on the institution level.

Most COIL courses can be a part of regular courses already being taught by faculty. What is different is that faculty are embedding PBL learning activities in the course, with the focus on action and reflection of students working in small global teams, rather than a focus on passively listening to delivered content by the instructor. Students have an authentic and wider audience that is counting on receiving student-produced content from, which can include the students in the other country or business or non-profit organization leaders that have posed the problem they seek to have the students solve or get valuable input on. This is the source for the enthusiasm that, when done well, motivates students to go beyond the minimum requirements, because they are now producing information and insights for a real audience they care about, and not just for some professor and a grade.

Therefore, the COIL-PBL model is about the guidance framework and a means to facilitate the collaboration process across different global institutions. The Great Debates course is the technical mechanism and content that helps in cultivating global citizenship among the participants.

Notably, after the emergence of the COVID-19 pandemic and imposition of restrictions on physical mobility, the COIL strategy has started to gain wider attention through funding and academic institutions such as the Stevens Initiative Connected Classrooms program which connects and supports multiple academic institutions in the United Arab Emirates, Morocco, and the USA to mainstream COIL in the curricula across the different social, hard, and natural sciences (Stevens Initiative, 2021). Therefore, the authors recommend future research to study the implementation of COIL courses in such universities using the COIL-PBL model to further develop and generalize the model. 


\section{References}

Ansar, J. A. A. N., \& Khan, N. A. (2020). Exploring the role of social media in collaborative learning the new domain of learning. Smart Learning Environments, 7(9).

Borcuch, A., Piłat-Borcuch, M., \& Świerczyńska-Kaczor, U. (2012). The influence of the internet on globalization process. Journal of Economics and Business Research, 18(1), 118-129. https://www.ceeol.com/search/article-detail?id=567731

Duhigg, C. (2016). What Google learned from its quest to build the perfect team. The New York Times Magazine. https:// centre.upeace.org/wp-content/uploads/2020/09/7.1-what-google-learnt.pdf

Farahani, M. F. (2014). The role of global citizenship education in world peace and security. Procedia-Social and Behavioral Sciences, 116, 934-938.

Gilbert, J. (2005). Catching the knowledge wave: the knowledge society and the future of education. NZCER Press.

Handa, N. (2018). Education for sustainability through internationalisation: transnational knowledge exchange and global citizenship. Palgrave Studies in Global Citizenship Education and Democracy. Springer.

Iva, K. M., Stephen, R., \& Nandini, V. (2012). Cross-national differences in global citizenship: comparison of Bulgaria, India, and the United States. Journal of Globalization Studies, 3(2).

Knight, J. (2004). Internationalization remodeled: definition, approaches, and rationales. Journal of Studies in International Education, 8(1), 5-31.

Krebs, K. C. (2020). Global, international, and intercultural learning in university classrooms across the disciplines. Research in Comparative and International Education, 15(1), 36-51.

PBLWorks. (n.d.). What is PBL. Buck Institute for Education. https://www.pblworks.org/what-is-pbl

Rapoport, A. (2020). Technologization of global citizenship education as response to challenges of globalization. Research in social sciences and technology, 5(1), i-vii.

Reade, C., Reckmeyer, W. J., Cabot, M., Jaehne, D., \& Novak, M. (2013). Educating global citizens for the 21st century: the SJSU Salzburg program. Journal of Corporate Citizenship, 49, 100-116.

Schattle, H. (2010). Global citizenship in theory and practice. In R. Lewin (Ed.), The handbook of practice and research in study abroad (pp. 25-42). Routledge.

Scheunpflug, A., \& Asbrand, B. (2006). Global education and education for sustainability. Environmental Education Research, 12(1), 33-46.

Sexton, D. (2018). Using campus resources and problem-based learning to prepare students to become global citizens.

In A. Traver \& D. Leshen (Eds), Humanistic pedagogy across the disciplines. Palgrave Macmillan.

Stearns, P. N. (2009). Educating global citizens in colleges and universities. Routledge.

Stevens Initiative. (2021). Stevens initiative connected classrooms. Aspen Institute. https://www.stevensinitiative.org/ project/stevens-initiative-connected-classrooms-cohort-1/

University of Minnesota Duluth. (n.d.). What is collaborative online international learning? http://d.umn.edu/coil/ World Economic Forum. (2018). The future of jobs report 2018. http://www3.weforum.org/docs/WEF_Future_of_Jobs_2018.pdf

Zinser, R. (2012). A curriculum model of a foundation for educating the global citizens of the future. On the Horizon, 20(1), 64-73. 


\section{Virtual Exchange?}

Published by University of Groningen Press | UGP, a not-for-profit press

Groningen, The Netherlands | UGP@rug.nl

(C) 2021 UNICollaboration (collective work)

(C) 2021 by Authors (individual work)

Journal of Virtual Exchange 2021

Edited by Carolin Fuchs and Müge Satar

Publication date: 2021/11/26

Journal of Virtual Exchange (JVE) is an online, open-access, peer-reviewed journal aimed at practitioners and researchers in the field known variously as virtual exchange, telecollaboration, or online intercultural exchange. It is the official journal of UNICollaboration (https://www.UNICollaboration.org/), the international academic organisation dedicated to supporting and promoting telecollaboration and virtual exchange in higher-level education.

Rights. The whole volume is published under the Attribution-NonCommercial-NoDerivatives 4.0 International licence (CC BY-NCND 4.0); individual articles may have a different licence. Under the CC BY-NC-ND licence, the volume is freely available online for anybody to read, download, copy, and redistribute provided that the author(s), editorial team, and publisher are properly cited. Commercial use and derivative works are, however, not permitted.

Disclaimer. University of Groningen Press does not take any responsibility for the content of the pages written by the authors of this article. The authors have recognised that the work described was not published before, or that it was not under consideration for publication elsewhere. While the information in this article is believed to be true and accurate on the date of its going to press, neither UniCollaboration nor University of Groningen Press can accept any legal responsibility for any errors or omissions. Additionally, the publisher makes no warranty, expressed or implied, with respect to the material contained herein. While University of Groningen Press is committed to publishing works of integrity, the words are the authors' alone.

Trademark notice. Product or corporate names may be trademarks or registered trademarks, and are used only for identification and explanation without intent to infringe.

Copyrighted material. Every effort has been made by the editorial team to trace copyright holders and to obtain their permission for the use of copyrighted material in this article. In the event of errors or omissions, please notify the publisher of any corrections that will need to by incorporated in future editions of this article.

Typeset by Research-publishing.net (https://research-publishing.net)

Noto fonts are open source. All Noto fonts are published under the SIL Open Font License, Version 1.1. Noto is a trademark of Google Inc. (https://www.google.com/get/noto/).

ISSN: 2647-4832 (online only)

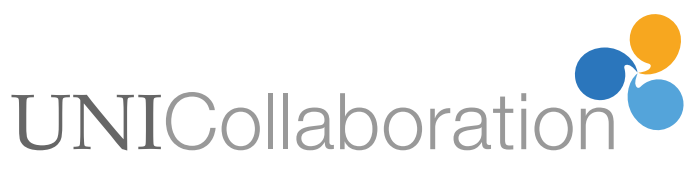

